\title{
Splenic rupture following splenic vein thrombosis in a man with protein $\mathrm{S}$ deficiency
}

\author{
N. Williams, C. Gerrand, N.J. London, C. Chapman' and P.R.F. Bell \\ Departments of Surgery and ${ }^{1}$ Haematology, Leicester Royal Infirmary, Infirmary Close, Leicester \\ LE1 $5 W W, U K$
}

\begin{abstract}
Summary: We present a case of spontaneous splenic rupture in a man with splenic vein thrombosis. The splenic vein thrombosis appears to have been caused by protein $\mathrm{S}$ deficiency. We are not aware of this having been described before.
\end{abstract}

\section{Introduction}

Splenic rupture is nearly always secondary to trauma. Of those that are not there is usually another underlying pathological process. The most commonly seen in the UK are those related to haematological malignancies. Splenic rupture has also been associated with viral infections (especially infectious mononucleosis), amyloidosis ${ }^{1}$ and rheumatoid disease. ${ }^{2}$ Splenic rupture may be associated with an haemangioma which is the commonest benign splenic tumour. ${ }^{3,4}$ We report the case of a male who presented with features of peritonitis and underlying disseminated intravascular coagulation, who developed a spontaneous rupture of the spleen, secondary to splenic vein thrombosis. We are not aware of this having been described before.

\section{Case history}

A 55 year old man presented with a 3 day history of lower abdominal pain. He had first attended on the previous day when he was pyrexial and was discharged with a provisional diagnosis of viral infection. On the day of presentation he had suffered a rigor and felt generally unwell. Ten months previously, he had suffered a spontaneous pulmonary embolism whilst mobile in the community. There were no underlying risk factors for deep vein thrombosis and he was thus warfarinized for 6 months. Nine years prior to this he had an episode of unexplained haemoptysis.

On examination, his abdomen was distended and tender in the suprapubic area with left-sided rectal tenderness. Haematological indices

Correspondence: N. Williams, F.R.C.S., University of Manchester, Hope Hospital, Eccles Old Road, Salford M6 8HD.

Accepted: 31 March 1992 (haemoglobin $14.2 \mathrm{~g} / \mathrm{dl}$, platelets $30 \times 10^{9} / 1$, white 0 cell count $\left.23.8 \times 10^{9} / 1\right)$ together with the clinical $\infty$ picture led to a provisional diagnosis of disseminated intravascular coagulation secondary $\overrightarrow{-}$ to pelvic sepsis. Abdominal ultrasound scan $Z$ showed free intraperitoneal fluid but normal liver, kidneys and spleen.

He suddenly deteriorated 4 hours later when he $\mathbb{\Phi}$ became profoundly hypotensive with markeg abdominal distention. Immediate laparotomy was performed and 5 litres of blood evacuated from the peritoneal cavity. Splenic rupture was confirmed and a splenectomy performed. It was noted that blood had tracked down the left paracolic gutter behind the peritoneum and the splenic vein was thrombosed.

On day 6 , he developed a pulmonary embolus, $\overrightarrow{\vec{O}}$ despite prophylactic heparin. This was confirmed by pulmonary angiography. A vena caval filter was inserted via the right transfemoral route and the patient given warfarin. Bone marrow aspiration showed reactive changes with increased megakaryocyte numbers consistent with peripheral consumption of platelets. There were no features to suggest a haematological malignancy. Histology of the spleen demonstrated a diffuse neutrophil infiltrate with prominent erythrophagocytosis by $ᄋ$ histiocytes. Scattered Warthin Finkeldey type giant $D$ cells were also present.

He was continued on warfarin and discharged home having made a full recovery. At review in the outpatients department he remained well and is $N$ asymptomatic. Investigations for an underlying $\mathrm{\omega}$ thrombotic state were carried out (Table I).

\section{Discussion}

This case presents many interesting facets. It is understandable that an initial diagnosis of severe 
Table I Phase I thrombophilia investigation

\begin{tabular}{lcc}
\hline Parameter & Value & Normal \\
\hline Thrombin clotting time & $17 / 17$ & \\
Fibrinogen & $0.5 \mathrm{~g}$ & $1.5-4.0$ \\
INR & 1.8 & $1.0-1.2$ \\
PTTK & 58 seconds & 40 seconds \\
LLAC & 0.99 & $0.7-1.09$ \\
Anticardiolipin antibody IgG & $<9$ & \\
Plasminogen activity & $94 \%$ & $83-153$ \\
Antithrombin III activity & $87 \%$ & $80-120$ \\
Protein C activity & $36 \%$ & $70-120$ \\
Protein S & & \\
Total & $38.5 \%$ & $60-135$ \\
Free & $20.0 \%$ & $56-119$ \\
Free \% total & $7.2 \%$ & $28-65$ \\
\hline
\end{tabular}

INR = international normalized ratio; PTTK = partial thromboplastin time with kaolin; LLAC = lupus-like anticoagulant.

pelvic sepsis was made at presentation as he had peritonitis with marked rectal tenderness on the left hand side. This would be consistent with his blood picture. Clearly his splenic rupture accounted for his acute deterioration. There was no history of recent trauma and no event occurred whilst he was in hospital. The likelihood therefore is that this was a spontaneous splenic rupture. The laparotomy findings of blood tracking down the left paracolic gutter would explain his acute abdomen and rectal tenderness.

The patient's past history and the development of a pulmonary embolus whilst on heparin suggested an underlying hypercoagulable state. There were no obvious underlying factors causing a thrombotic tendency in this patient and he therefore underwent further haematological assessment. The results shown in Table I were those obtained whilst the patient was on warfarin. The value for antithombin III is normal as is that for protein $\mathrm{C}$ for a patient on warfarin. Protein $S$ levels are also reduced in warfarin therapy but, in this case, the values are much lower than expected for warfarin levels. Generally, a value of $<8 \%$ for the free percentage of the total $(\mathrm{F} \% \mathrm{~T})$ represents a significant result. Protein $\mathrm{S}$ deficiency is a recognized cause of an hypercoagulable state. The aetiology is almost certainly genetic as there is a familial tendency. Genetic analysis of several families have suggested that spontaneous point mutation is the most likely cause of this deficiency state. In one study of 71 protein S-deficient patients, $74 \%, 72 \%$ and $38 \%$ had sustained deep venous thrombosis, superficial thrombophlebitis or pulmonary emboli, respectively. ${ }^{5}$ Thromboses have also been reported in the axillary, mesenteric and cerebral veins. Of the total protein $\mathrm{S}$ antigen in plasma under normal conditions, $60 \%$ is complexed to the complement protein C4b. Only the free $40 \%$ is functionally active as a co-factor in mediating the anticoagulant effects. Interpretation of protein $\mathrm{S}$ measurements in patients on warfarin is complicated as the antigenic and functional levels of the protein drop substantially. In order to further confirm that the low levels seen in this patient were significant, the protein $S$ values would have to be repeated with the patient off warfarin.

Histological assessment of the spleen was inconclusive as to the cause of the rupture. The presence of neutrophil infiltration with erythrophagocytosis by histiocytes may be consistent with splenic trauma but it may also be due to infection. The presence of Warthin Finkeldey type giant cells would suggest a viral infection. However, whilst there may have been a viral infection that precipitated the splenic rupture, clearly the underlying thrombotic tendency affected the natural history at presentation and in his subsequent recovery. In the acute event there was no way of identifying conclusively the cause of his thrombotic tendency and so low-dose heparin was used. In the event he developed a life-threatening pulmonary embolus whilst on low-dose heparin and was subsequently fully anticoagulated.

At 6 months follow-up he remains well and has had no further thrombotic episodes. It is planned to continue him on long term warfarin.

\section{References}

1. Kozoiky, O.J., Brandt, L.J., Lederman, M. et al. Splenic amyloidosis, a case report of spontaneous splenic rupture with a review of the pertinent literature. Am J Gastroenterol 1987, 82: 582-587.

2. Marcus, R.W. Rupture of the spleen in rheumatoid arthritis. Ann Rheum Dis 1985, 44: 142.

3. Husni, E.A. The clinical course of splenic haemangioma. Arch Surg 1961, 83: 681-684.

4. Kaplan, J. \& McIntosh, G.S. Spontaneous rupture of a splenic vascular malformation. $J R$ Coll Surg Ed 1987, 32: 346-347.

5. Engesser, L., Broekmans, A.W., Briet, E. et al. Hereditary protein S deficiency: clinical manifestations. Ann Intern Med 1987, 106: 677-682. 